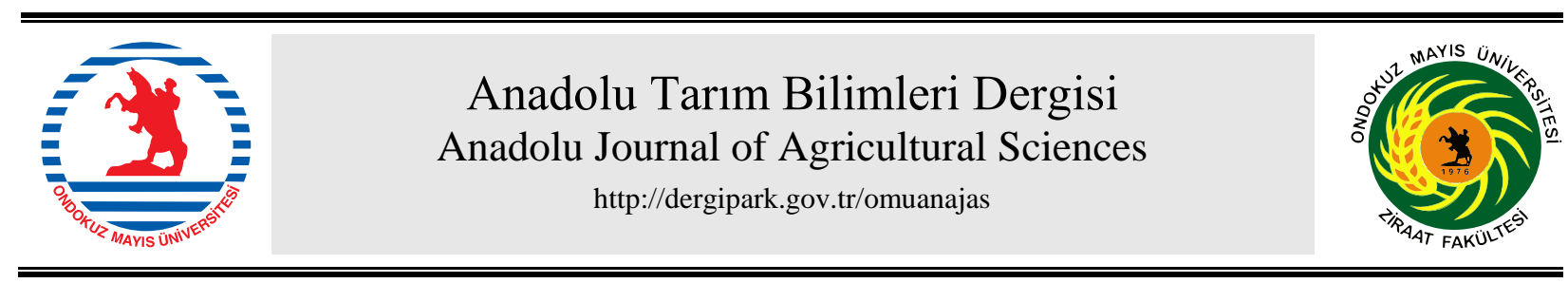

Araştırma/Research

Anadolu Tarım Bilim. Derg./Anadolu J Agr Sci, 35 (2020)

ISSN: 1308-8750 (Print) 1308-8769 (Online)

doi: $10.7161 /$ omuanajas. 641480

\title{
Soyanın agronomik parametreleri ile toprağın bazı fiziksel ve kimyasal özellikleri arasındaki doğrusal regresyon ilişkilerin belirlenmesi
}

\author{
İmanverdi Ekberli $\mathrm{a}^{*}$ \\ Nalan Kars ${ }^{\mathrm{b}}$ \\ ${ }^{a}$ Ondokuz Mayıs Üniversitesi, Ziraat Fakültesi Toprak Bilimi ve Bitki Besleme Bölümü, Samsun, Türkiye \\ ${ }^{b}$ T.C. Tarım ve Orman Bakanlı̆̆l, Karadeniz Tarımsal Araştırma Enstütüsü Müdürlüğ̈̈, Samsun,Türkiye
}

*Sorumlu yazar/corresponding author: iman@omu.edu.tr

\begin{abstract}
Geliș/Received 01/11/2019 Kabul/Accepted 30/12/2019
ÖZET

$\mathrm{Bu}$ çalışmanın amacı, Çarşamba Ovası'nda yetiştirilen soya bitkisinin verim parametreleriyle (bitki boyu, bin tane ağırlı̆ı ve tane verimi) toprakların bazı fiziksel ve kimyasal özellikleri arasındaki korelasyon ilişkilerine dayanarak, bu özellikler arasında regresyon modellerin oluşturulması ve elde edilen modellerin ova topraklarında bitki veriminin tahmininde uygulanabilirliğinin belirlenmesidir. $\mathrm{Bu}$ amaçla, ovanın çiftçiler tarafından soya tarımı yapılan arazilerinden toprak ve bitki örnekleri alınmıştır. Bitki boyu ile kil, hacim ağırlığı $(\mathrm{Db})$, elektriksel iletkenlik (EC), organik madde $(\mathrm{OM})$, azot $(\mathrm{N})$, potasyum (K), bitkiye yarayışlı su (BYS), solma noktası (SN) parametreleri arasındaki regresyon modeli istatistiksel olarak anlamlı $(\mathrm{p}=0.091)$, belirleme katsayısı $(\mathrm{R}=0.766)$ yüksek; bin tane ağırlığ 1 ile $\mathrm{OM}, \mathrm{Db}$, kum, silt, kireç $\left(\mathrm{CaCO}_{3}\right)$, katyon değişim kapasitesi (KDK), N, fosfor (P), K, sodyum (Na), tarla kapasitesi (TK), SN parametreleri arasindaki model istatistiksel olarak anlamlı farklılık saptanmamış, belirleme katsayısı $(\mathrm{R}=0.782)$ yüksek; tane verimi ile $\mathrm{OM}, \mathrm{KDK}, \mathrm{N}, \mathrm{P}$, bakır $(\mathrm{Cu})$, kil, kum, BYS, TK parametreleri arasındaki modelin performansı çok yüksek $(\mathrm{R}=0.853 ; \mathrm{p}=0.029)$ olarak belirlenmiştir. Verim parametreleri ile toprakların fiziksel ve kimyasal özellikleri arasındaki regresyon modellerin geçerliliğinin belirlenmesinde belirleme katsayısı (R), hata kareler ortalamasının karekökü (HKOK), uygunluk indeksi (d), modelin etkinliği (ME) birlikte değerlendirilmiştir. Elde edilen regresyon modellerin, ova topraklarında yetiştirilen soya bitkisinin verim parametrelerinin tahmin edilmesinde uygulanabilirliği mümkün gözükmektedir.
\end{abstract}

Creation of Liner Regression Models Between Yield Parameters of Soybean Plant and Some Physical and Chemical Properties of Soil

\section{ABSTRACT}

The aim of this study was to develop regression models on the basis of correlation between yield parameters of soybean (plant height, thousand seed weight, and yield) and some physical and chemical characteristics of soils and to determine applicability of obtained models in estimation of plant yield grown in soils of Çarşamba Plain. Soil and plant samples were taken from farmer's fields in the plain. Regression models between soybean plant height and soil properties of bulk density (BD), electrical conductivity (EC), organic matter $(\mathrm{OM})$, nitrogen $(\mathrm{N})$, potassium $(\mathrm{K})$, wilting point $(\mathrm{WP})$, available water content $(\mathrm{AWC})$ and clay yielded high coefficient determination $(\mathrm{R}=0.766)$ and was significant $(\mathrm{p}=0.091)$; Model between thousand seed weight and $\mathrm{OM}, \mathrm{BD}$, sand, silt, lime $\left(\mathrm{CaCO}_{3}\right)$, cation exchange capacity (CEC), N, phosphorus (P), K, sodium (Na), field capacity (FC) and WP, resulted in $\mathrm{R}=0.782$ and was insignificant; and model between seed yield and $\mathrm{OM}, \mathrm{CEC}, \mathrm{N}, \mathrm{P}, \mathrm{copper}(\mathrm{Cu})$, clay, sand, AWC, and FC yielded $\mathrm{R}=0.853$ and it was highly significant $(\mathrm{p}=0.029)$. Determination coefficient (R), root mean square error (RMSE), index of agreement (d), model efficiency (ME) were evaluated together to determine the validity of regression models. In general, statistical parameters were within validity limits. The results suggested that the developed regression models can be applied in the Anahtar Sözcükler: Bitki boyu Bin dane ağırlı̆̆ Regresyon modeller Toprak özellikleri Verim estimation of yield parameters in soybean grown in study area.

Keywords:

Plant height

Properties of soils

Regression models

Thousand seed weight Yield

(C) OMU ANAJAS 2020 


\section{Giriş}

Mevcut tarım arazileriyle artan dünya nüfusunun beslenme ihtiyaçlarını karşılamak için, birim tarım arazisinden daha yüksek verim alınması gereksinimi ortaya çımakta, verimliliğinin artırılması ve tahmin edilmesi güncel ve araştırma önceliği olan konulardan biri olmaktadir.

Yüksek verim elde edilmesi çeşitli ekolojik, çevresel ve genetik faktörlerle beraber toprağın fiziksel, kimyasal, biyolojik özelliklerine bağlıdır. Bu nedenle, araştırmacılar (Hallauer ve Miranda, 1987; Taban ve ark., 2004; Ekberli ve Kerimova, 2005; Ekberli ve Dengiz, 2016; Kars ve Ekberli, 2019a) tarafindan toprakların fiziksel ve kimyasal özelliklerinin ve bu özelliklerle çeşitli bitkilerin verim parametreleri arasındaki deneysel ilişkinin belirlenmesine; verimliliğin korunmasına, tahmin edilmesine ve artırılmasına yönelik yöntemlerin oluşturulması gerekliliği vurgulanmıştır.

Yapılan birçok araştırmada bitki boyu, bin tane ağırlığı ve tane veriminin; genotip, çevre şartları, ekim sıklığ 1 gibi faktörlerle beraber toprak özelliklerine önemli düzeyde bağlı olarak değiştiği bildirilmektedir (Whitman ve ark., 1985; Dotlacil ve Toma, 1991; Peterson ve ark., 1992; Maiti ve Wesche-Ebeling, 1998).

Karadeniz bölgesinde en önemli tarımsal potansiyele sahip olan Çarşamba Ovası'nda, soya bitkisinin ekim alanı 659 ha, üretimi 2796 ton ve verimi ise $424 \mathrm{~kg} \mathrm{da}$ ${ }^{1}$ 'dır (Anonim, 2016).

Toprakların fiziksel, kimyasal, biyolojik özellikleri, iklim koşulları, toprak işleme yöntemleri, tohum çeşidi gibi faktörler soya bitkisinin verimliliğine önemli düzeyde etki yapmaktadır. Valdivia (1983), soyanın tane verimi ile yetişme süresi, bitki boyu, ilk bakla yüksekliği, bin tane ağırlığı, çiçeklenme süresi ve bitkideki bakla sayısı arasında önemli bir ilişki saptamıştır. Bitki boyu ile bitkideki bakla sayısı arasında zayıf, tane verimi ile ise önemli pozitif korelasyonun olduğu araştırmacilar tarafindan bildirilmiştir (Marin, 1975; Manzoor ve Kaleri, 1971; Simpson ve Wilcox, 1983).

Regresyon modellerin ekoloji, hidroloji, çeşitli mühendislik dallarında olduğu gibi, tarım alanında da geniş uygulamaları vardır.

Toprak biliminde toprak özelliklerine ait yeterli düzeyde verilerin birikimine paralel olarak, regresyon modellerin amaca uygun olarak kullanımı ortaya çıkmıştır.

Toprak ve bitki ekosisteminde regresyon modellerin yapılması ve kullanılması teorik modellerden (Bayraklı ve ark., 1999; Overman ve Scholtz, 2002; Gülser, 2004; Huang ve ark., 2014; Dorsey ve Hardy, 2018; Thiery ve ark., 2018; Kars ve Ekberli, 2019b) daha kolay ve pratik olmaktadır. Deneysel ve teorik modellerin yapılmasında, birçok varsayımlar kabul edilmekte, benzer etkilere sahip parametrelerin az sayida kullanılması söz konusu olmaktadır (Bouma ve van Lanen, 1987; Pachepsky ve Rawls, 2004).

Regresyon modellerin yardımıyla, çeşitli bitkilerin agronomik parametreleri (bitki boyu, bin tane ağırlığı, tane verimi gibi) ile toprağın bazı fiziksel ve kimyasal özellikleri arasındaki nicel ilişkiler açıklanabilmektedir.

Araştırmacılar tarafindan yapılan regresyon modellerinde bağımsız parametreler olarak; daha kolay belirlenebilen toprak kimyasal ve fiziksel özellikleri tercih edilmektedir (Campbell ve Shiozawa, 1992; Vereecken ve ark., 2010; Gülser ve ark., 2016; Dengiz ve Ekberli, 2017).

Regresyon modellerinin geçerliliğinin belirlenmesinde farklı istatiksel parametrelerden kullanılması, model oluşturulmasında önemli ve gerekli aşamalardan biridir.

Birçok araştırmacı tarafından regresyon modellerinin uygulanabilirliğini belirlemek için; hata kareler ortalamasının karekökü (HKOK), uygunluk indeksi (d), maksimum nispi hata (MNH), mutlak hata $(\mathrm{MH})$, belirleme katsayıs1 (R) gibi istatistiksel parametreler kullanılmıştır (Alexandrov ve Hoogenboom, 2000; Budka ve ark., 2015).

$\mathrm{Bu}$ araştırma; Çarşamba Ovası'nda geleneksel toprak işleme yöntemiyle soya yetiştirilen tarım topraklarının bazı fiziksel ve kimyasal özellikleri ile soya bitkisinin agronomik parametreleri arasındaki korelasyon ilişkilere dayanarak, bu özellikler arasında regresyon modellerin oluşturulması ve elde edilen modellerin ova topraklarında bitki veriminin tahmininde uygulanabilirliğinin belirlenmesi amacıyla yürütülmüştür.

\section{Materyal ve Yöntem}

Araştırma; 2013-2014 yıllarında Samsun ili Çarşamba Ovası'nı temsil eden 20 köyde, çiftçiler tarafindan tarım yapılan arazilerden $0-20 \mathrm{~cm}$ derinlikten her yıl için 20 toprak örneği alınarak gerçekleştirilmiştir. Aynı alanlardan bitki örneklerinin alınmasında Anonim (2013)'de gösterilen yöntem kullanılmıştır. Toprak ve bitki örneklerinin alındığı lokasyonlar Şekil 1'de gösterilmiştir.

Samsun ili sınırları içerisinde yer alan Çarşamba Ovası, güneyde Canik dağları ile kuzeyde ise Karadeniz ile sınırı bulunan Yeşilırmak'ın oluşturduğu bir delta ovasıdır. Ova 0-50 m kotları arasında, 103766 hektarlık bir alanı kapsamaktadır.

Çarşamba Ovası doğu-batı istikametinde $65 \mathrm{~km}$, güney-kuzey istikametinde ise $35 \mathrm{~km}$ uzunluğa sahiptir. Ova taban arazilerinin genel eğimleri güney-kuzey istikametinde olup ortalama eğim \% 0.1 'dir. Bu eğim, deniz kenarına yaklaştıkça \% $0-0.02$ 'ye kadar düşmektedir. Yamaç arazilerde ise eğim, \% 2-40 arasında değişmektedir. 
Ova; bitki örtüsü yönünden çok zengin olup, 58921 hektar tarım arazisine sahiptir. Ovada soya bitkisi 659 hektar alanda yetiştirilmektedir.

Ova toprakları alüviyal ve kısmen de kolüviyal (kestane rengi topraklar, gri-kestane podzolik topraklar, kahverengi orman toprakları) karakterdedir (Anonim, 1984).

Ovada yıllık toplam yağış miktarı $985.9 \mathrm{~mm}$ olup, y1llık sicaklık ortalaması ise $15-17{ }^{\circ} \mathrm{C}$ 'dir (Turan ve ark., 2018).

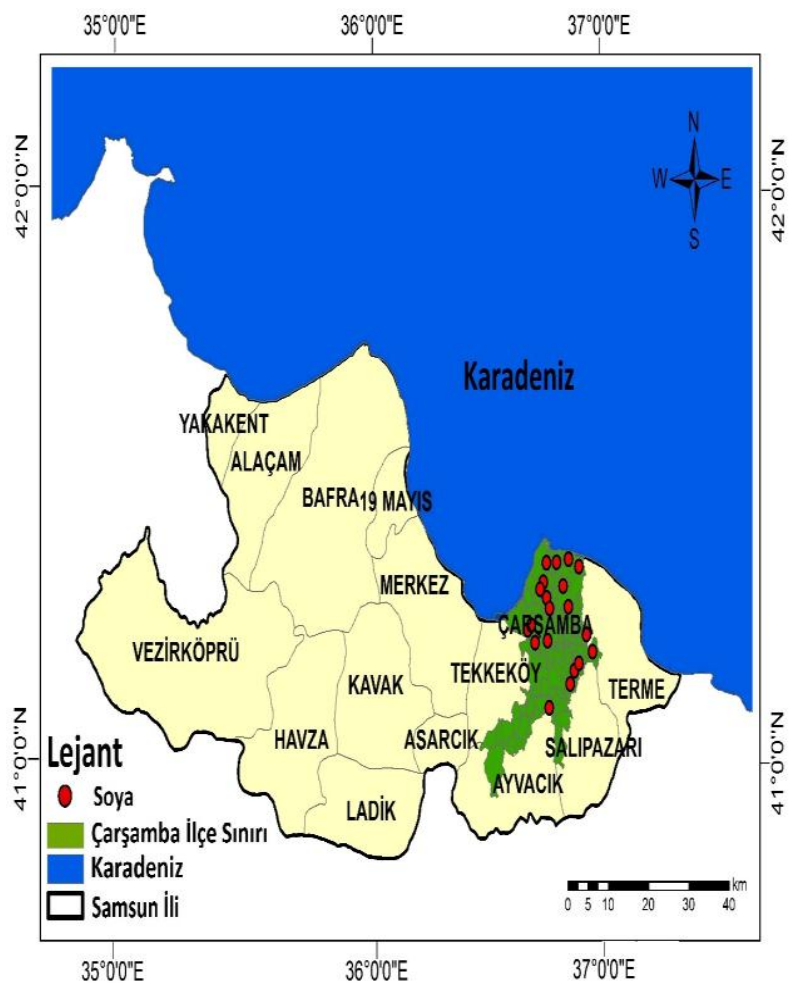

Şekil 1. Araştırma alanının konumu, toprak ve bitki örneklerinin alındığı noktalar

Figure 1. Location of the research area, points of soil and plant samples

Alınan toprak örneklerinde tekstür hidrometre yöntemiyle (Demiralay, 1993); hacim ağırlığı Demiralay (1993)'a göre; toprak reaksiyonu (pH), 1:1 oranında hazırlanan toprak-su süspansiyonunda cam elektrotlu pH metre ile (Bayrakl1, 1987); elektriksel iletkenlik (EC), 1:1 oranında hazırlanan toprak-su süspansiyonunda elektriksel kondaktivite aleti ile (Richards, 1954); kireç $\left(\mathrm{CaCO}_{3}\right), \quad$ Scheibler kalsimetresiyle volümetrik olarak (Kacar, 1994); organik madde (OM), Walkley-Black yaş yakma yöntemine göre (Kacar, 1994) ve toplam azot (N) Kjeldahl yaş yakma yöntemine göre (Kacar, 1994) belirlenmiştir.

Toprakların yarayışlı fosfor (P) içeriği, mavi renk yöntemine göre (Olsen ve ark., 1954); değişebilir potasyum $(\mathrm{K})$ ve sodyum $(\mathrm{Na})$, toprak örneğinin $1 \mathrm{~N}$ amonyum asetat $(\mathrm{pH}=7.0)$ çözeltisi ile ekstrakte edilmesiyle, kalsiyum $(\mathrm{Ca})$ ve magnezyum $(\mathrm{Mg}) 0.01 \mathrm{M}$ EDTA titrasyonu ile (Sağlam, 1997); katyon değişim kapasitesi (KDK), Bower yöntemine göre (Anonymous, 1954); alınabilir demir (Fe), bakır (Cu), mangan ( $\mathrm{Mn})$ ve çinko (Zn) içerikleri ise Lindsay ve Norvell (1978) tarafindan bildirildiği şekli ile $(0.005 \mathrm{M}$ DTPA + 0.01 $\mathrm{M} \mathrm{CaCI}_{2}+0.1 \mathrm{M} \mathrm{TEA}, \mathrm{pH}=7.3$ ) tespit edilmiştir.

Tarla kapasitesi (TK) ve solma noktası (SN) değeri, basınçlı tabla aletinde sırasıyla $1 / 3$ atm ve 15 atm basınç altında toprak örneklerinin hidrolik denge durumuna gelmesinden sonra ağırlık esasına göre (Black, 1965); bitkiye yarayışlı su miktarı (BYS), TK ve SN arasındaki farktan hesaplanmıştır.

Soya bitkisinde bitki boyu (BB), bin tane ağırlığı (BTA) ve tane verimi (TV) ölçümleri, Anonim (2013) tarafından bildirilen esaslar çerçevesinde yapılmıştır.

Toprak ve bitki analiz sonuçlarına ait tanımlayıcı istatistikler ile toprak özellikleri ve bitki agronomik parametreleri arasındaki korelasyonlar SPSS 17.0 paket programında hesaplanmış, agronomik parametreleri ile toprak özellikleri arasında oluşturulan regresyon modeller ise, Minitab 17.0 paket programında oluşturulmuştur.

Hata kareler ortalamasının karekökü (HKOK), uygunluk indeksi (d) ve model etkinliği (ME) sırasıyla aşağıdaki eşitlikler kullanılarak hesaplanmıştır:

$$
\text { HKOK }=\sqrt{\frac{1}{n} \sum_{i=1}^{n}\left(x_{i}-y_{i}\right)^{2}}
$$

Eşitlik 1'de, n-verilerin sayı ve ise , ise $m=n$; ölçülen; - hesaplanan değerlerdir.

$$
d=1-\frac{\sum_{i=1}^{n}\left(x_{i}-y_{i}\right)^{2}}{\sum_{i=1}^{n}\left(\left|x_{i}-\bar{y}\right|+\left|y_{i}-\bar{y}\right|\right)^{2}}
$$

Eşitlik 2'de, ve sırasıyla hesaplanan ve ölçülen değerlerin ortalamasını ifade etmektedir.

$$
M E=1-\frac{\sum_{i=1}^{n}\left(x_{i}-y_{i}\right)^{2}}{\sum_{i=1}^{n}\left(y_{i}-\bar{y}\right)^{2}}
$$

Hata kareler ortalamasının karekökü (HKOK), tahmin hatalarının standart sapmasını ifade etmektedir. Uygunluk indeksi (d) modelin geçerliliğinin bir göstergesi olup, d'nin 1'e yakın olması modelin uygulanabilirliğini göstermektedir.

Krause ve ark. (2005) tarafindan, deneysel hidrolojik modele yönelik bir araştırmada, ME değerlerinin 1 (mükemmel uyum) ile arasında değiştiği gösterilmiş; ME’nin sıfirdan küçük olması durumunda ise ölçülen ortalama değerin, hesaplanan değerden daha 
etkin olduğu belirtilmiştir. d ve ME'nin analitik ifadelerinin karşılaştırılmasından da görüldüğü gibi, genel olarak d ME'den daha büyük değerler almaktadır (Willmott ve Matsuura, 2005; Willmott ve ark., 2012; Kumar ve ark., 2015).

\section{Bulgular ve Tartışma}

\subsection{Soyanın agronomik parametreleri}

Araştırma alanında yetiştirilen soyanın bazı agronomik parametrelerine ilişkin tanımlayıcı istatistikler Çizelge 1'de verilmiştir.

Çizelge 1'den görüldüğü gibi, soya bitkisinin BB, BTA ve TV değerleri sirasıyla; 88.33-127.27 cm, $164.10-242.91 \mathrm{~g}$ ve $280.32-593.16 \mathrm{~kg} \mathrm{da}^{-1}$ arasinda değişmekte, ortalama değerleri ise sırasıyla $103.31 \mathrm{~cm}$, $200.54 \mathrm{~g}$ ve $455.87 \mathrm{~kg} \mathrm{da}^{-1}$ olmaktadır.

Görüldügü gibi, istatistiksel göstergeler geçerli sinırlar (Willmott ve Matsuura, 2005) dahilinde değişmektedir. Bitki boyu ve bin tane ağırlığına ait standart sapma değerleriyle karşılaştırıldığında tane veriminin standart sapmasının yüksek olmasının nedeni, tane veriminin geniş aralıkta değișimi olabilir. Varyasyon katsayis1 $(<20)$ ise verilerin homojen dağglıma sahip olduğunu göstermektedir.

Çarpıklık değerleri ise, sağdan ve soldan sıfıra yakın olmakta, dolayısıyla dağılımın genel olarak normale yakın olduğunu göstermektedir.

Soyada bitki boyu; çeşit, ekim sıklığı, ekim zamanı ve yetiştirme şartlarına bağlı olarak, $30-150 \mathrm{~cm}$ arasında değişim göstermektedir (Arıoğlu, 2000).

Homer ve ark. (2000), Karadeniz Bölgesinin sahil ve geçit bölgelerine uygun soya çeşitlerini belirlemek ve geliştirmek amacıyla yapmış oldukları bir çalışmada, bitki boylarının $72.9 \mathrm{~cm}$ ile $128.8 \mathrm{~cm}$ arasında, bin tane ağırlığın $\quad 157.0 \mathrm{~g}$ ile $298.0 \mathrm{~g}$ arasında değiştiğini bildirmişlerdir.

Soya verimini esas olarak tane ağırlığı ve tane sayısı belirlemekte ve tane sayısı birim alandaki bakla sayısına ve bakladaki tane sayısına bağlı olmaktadır (Karagül ve ark., 2011).

Ay (2012) tarafindan, Türkiye'de sslah edilmiş yeni soya (Glycine max. 1. merrill) çeşitlerinin Orta Karadeniz Bölgesi koşullarında verim ve kalite performanslarının belirlendiği bir çalışmada, Terme'de en yüksek tane veriminin $570.68 \mathrm{~kg} \mathrm{da}^{-1}$ ile Erensoy çeşidinde; en düşük tane verimin ise $335.50 \mathrm{~kg} \mathrm{da}^{-1}$ ile Üstün 1 çeşidinden elde edildiği bildirilmiştir.

\subsection{Soya tarımı yapilan toprakların fiziksel ve kimyasal özelliklerinin değişimi}

Ovada soya fasülyesi yetiştirilen toprakların bazı fiziksel ve kimyasal özelliklerine ait tanımlayıcı istatistikler Çizelge 2'de verilmiştir.

Çizelge 2'den görüldüğü gibi, araştırma topraklarının fiziksel özelliklerine ait tanımlayıcı istatistik değerleri güvenirlilik sınırları dahilinde değişmektedir.

Sağa ve sola çarpıklık değerleri sıfıra yakın olmakta, dolayısıyla toprakların fiziksel özellikleri normale yakın dağılım göstermektedir.

Kültivasyon işlemleri ve organik madde, kireç, gübreler ve sentetik toprak düzenleyicilerinin toprağa ilavesi gibi antropojenik etkiler toprak özelliklerinin ( $\mathrm{P}$, $\mathrm{CaCO}_{3}, \mathrm{Ca}+\mathrm{Mg}$ ) geniş aralıkta değişimine, dolayısıyla değerlerin heterojen dağılımına ve varyasyon katsayılarının yüksek olmasına sebep olabilir.

Çizelge 1. Soyanın bazı agronomik parametrelerine ilişkin bazı tanımlayıcı istatistikler $(n=40)$

Table 1. Some descriptive statistics related to some agronomic parameters of soybean $(n=40)$

\begin{tabular}{lcccccc}
\hline Özellikler & En düşük & En yüksek & Ortalama & Standart sapma & $V K, \%$ & Çarpıklık \\
\hline BB, cm & 88.33 & 127.27 & 103.31 & 9.91 & 9.59 & 1.127 \\
BTA, g & 164.10 & 242.91 & 200.54 & 17.81 & 8.88 & 0.505 \\
TV, kg da & 280.32 & 593.16 & 455.87 & 81.71 & 17.92 & -0.410 \\
\hline
\end{tabular}

BB: Bitki boyu, BTA: Bin tane ağırlı̆ı̆, TV: Tane verimi, $V K$ : Varyasyon katsayısı 
Çizelge 2. Soya bitkisi yetiştirilen toprakların bazı fiziksel ve kimyasal özelliklerine ait bazı tanımlayıcı istatistikler Table 2. Descriptive statistics about some physical and chemical features of soybean grown soils

\begin{tabular}{|c|c|c|c|c|c|c|}
\hline Özellikler & En düşük & En yüksek & Ortalama & Standart Sapma & $V K, \%$ & Çarpıklık \\
\hline Kil, \% & 15.34 & 57.23 & 37.67 & 12.74 & 33.82 & -0.218 \\
\hline Silt, \% & 12.19 & 54.02 & 37.04 & 11.14 & 30.07 & -0.752 \\
\hline Kum, \% & 11.67 & 42.15 & 25.27 & 9.19 & 36.36 & 0.429 \\
\hline $\mathrm{Db}, \mathrm{g} \mathrm{cm}^{-3}$ & 0.96 & 1.50 & 1.21 & 0.15 & 12.39 & 0.143 \\
\hline $\mathrm{TK}, \%$ & 25.59 & 49.19 & 37.54 & 6.18 & 16.46 & 0.045 \\
\hline $\mathrm{SN}, \%$ & 12.78 & 32.11 & 20.82 & 4.97 & 23.87 & 0.664 \\
\hline BYS, $\%$ & 12.55 & 23.01 & 16.71 & 2.56 & 15.32 & 0.203 \\
\hline $\mathrm{pH},(1: 1)$ & 7.00 & 8.02 & 7.72 & 0.21 & 2.72 & -1.566 \\
\hline $\mathrm{EC}, \mathrm{dS} \mathrm{m}^{-1}(1: 1)$ & 0.40 & 0.98 & 0.60 & 0.14 & 23.33 & 0.881 \\
\hline $\mathrm{CaCO}_{3}, \%$ & 0.55 & 13.45 & 5.84 & 4.08 & 69.86 & 0.154 \\
\hline $\mathrm{OM}, \%$ & 1.61 & 5.05 & 2.89 & 1.03 & 35.64 & 0.724 \\
\hline $\mathrm{N}, \%$ & 0.11 & 0.30 & 0.15 & 0.04 & 26.66 & 1.571 \\
\hline $\mathrm{P}, \mathrm{ppm}$ & 1.74 & 38.26 & 13.68 & 10.08 & 73.68 & 0.890 \\
\hline $\mathrm{K}, \mathrm{cmol} \mathrm{kg}^{-1}$ & 0.17 & 1.17 & 0.56 & 0.20 & 35.71 & 0.783 \\
\hline $\mathrm{Ca}+\mathrm{Mg}, \mathrm{cmol} \mathrm{kg}^{-1}$ & 29.03 & 94.39 & 50.52 & 17.02 & 308.33 & 0.692 \\
\hline $\mathrm{Na}, \mathrm{cmol} \mathrm{kg}^{-1}$ & 0.35 & 2.46 & 1.37 & 0.70 & 51.09 & -0.346 \\
\hline $\mathrm{KDK}, \mathrm{cmol} \mathrm{kg}^{-1}$ & 30.05 & 96.96 & 52.47 & 17.30 & 32.97 & 0.693 \\
\hline $\mathrm{Fe}, \mathrm{ppm}$ & 21.99 & 60.74 & 33.85 & 9.65 & 28.50 & 0.858 \\
\hline $\mathrm{Mn}, \mathrm{ppm}$ & 4.95 & 31.49 & 11.68 & 5.27 & 45.11 & 2.679 \\
\hline $\mathrm{Cu}, \mathrm{ppm}$ & 2.27 & 9.37 & 5.81 & 1.61 & 27.71 & 0.031 \\
\hline $\mathrm{Zn}, \mathrm{ppm}$ & 0.29 & 1.26 & 0.58 & 0.19 & 32.75 & 1.503 \\
\hline
\end{tabular}

Db: Hacim ağırlı̆̆ı; TK: Tarla kapasitesi; SN: Solma noktası; BYS: Bitkiye yarayışlı su; pH: Toprak reaksiyonu; EC: Elektriksel iletkenlik; $\mathrm{CaCO}_{3}$ : Kireç; OM: Organik madde; N: Azot; P: Fosfor; K: Potasyum; Ca+Mg: Kalsiyum+Magnezyum; Na: Sodyum; KDK: Katyon değişim kapasitesi; Fe: Demir; Mn: Mangan; Cu: Bakır; Zn: Çinko; VK: Varyasyon katsayısı.

3.3. Soya bitkisinin bazı agronomik parametreleri ile toprağın bazı fiziksel ve kimyasal özellikleri arasındaki ilişkiler

Soya bitkisinin agronomik parametreleri ile toprağın bazı fiziksel ve kimyasal parametrelerine ait korelasyon katsayıları (r) Çizelge 3 'te verilmiştir. Soya bitkisinin BB değeriyle BTA'1 arasında önemli pozitif $\left(0.476^{*}\right)$; BB ile topraklardaki $\mathrm{Cu}$ miktarı arasında ise çok önemli pozitif ilişkiler $\left(0.484^{* * *}\right)$ belirlenmiștir. Soya bitkisinin TV değeri ile topraklardaki $\mathrm{K}$ ve $\mathrm{P}$ miktarları arasında önemli pozitif ilişkiler $\left(0.384^{*}\right.$ ve $\left.0.382^{*}\right)$ saptanmıştır. Soya bitkisinin BTA'1 ve toprakların Na içeriği arasında önemli pozitif ilişki $\left(0.389^{*}\right)$ belirlenmiştir. Soya bitkisinin verim parametreleriyle, toprakların diğer fiziksel ve kimyasal parametreleri arasında ise istatistiksel açıdan önemli bir ilişki saptanmamıştır. Soya tane verimi üzerine, bakla sayısı doğrudan etkiye sahip olmakta; tane verimi ve 100 tane ağırlığ 1 arasında önemli derecede ve pozitif ilişki bulunmaktadır (Rajput ve ark., 1987). Çetin (2010), soya bitkisinin verim ve bazı kalite özelliklerine ait bir araştırmada, fosforun bitki boyu üzerine etkisini önemli bulurken, bin tane ağırlı̆̆ üzerine etkisini ise önemsiz bulmuştur. Arslanoğlu ve ark. (2005), Karadeniz Bölgesi'nde 2 yıl süreyle yürüttükleri farklı farklı olgunlaşma süresine sahip soya çeşitlerinin verim potansiyellerinin belirlendiği araştırmada; dekara verim ile bitki boyu arasında pozitif önemli ilişki bulmuşlardır. Tayyar ve Gül (2007) tarafından yapılan bir araştırmada, iki yıllık deneme sonuçlarına göre verim ile bitki boyu arasında $\left(\mathrm{r}=0.30^{* *}\right)$ pozitif önemli bir ilişki saptanmıştır.

3.4. Agronomik parametreleri ile topraklarn bazı fiziksel ve kimyasal özellikleri arasindaki regresyon modeller

Soya bitki boyu, bin tane ağırlığı ve tane verimi ile toprakların bazı fiziksel ve kimyasal özellikleri arasındaki regresyon modeller Çizelge 4'de verilmiştir. Regresyon modellerinin oluşturulmasında verim parametreleri ile toprakların bazı fiziksel ve kimyasal özelliklerine ilişkin korelasyon analiz sonuçları Çizelge 3 'te verilmiştir. 
Çizelge 3. Soya'nın bazı agronomik parametreleri ile toprağın kimyasal ve fiziksel özelliklerine ait korelasyon matrisi

Table 3. Correlation matrix of some agronomic parameters of soybean with chemical and physical properties of soil

\begin{tabular}{|c|c|c|c|}
\hline Özellikler & $\mathrm{BB}, \mathrm{cm}$ & BTA, g & $\mathrm{Y}, \mathrm{kg} \mathrm{da}^{-1}$ \\
\hline $\mathrm{BB}, \mathrm{cm}$ & 1 & & \\
\hline BTA, g & $0.476^{*}$ & 1 & \\
\hline $\mathrm{TV}, \mathrm{kg} \mathrm{da}^{-1}$ & 0.199 & 0.131 & 1 \\
\hline Kil, \% & 0.076 & 0.056 & 0.166 \\
\hline Silt, \% & -0.092 & 0.082 & -0.032 \\
\hline Kum, \% & 0.006 & -0.178 & -0.191 \\
\hline $\mathrm{Db}, \mathrm{g} \mathrm{cm}^{-3}$ & 0.005 & -0.150 & 0.236 \\
\hline $\mathrm{TK}, \%$ & -0.015 & 0.143 & 0.237 \\
\hline $\mathrm{SN}, \%$ & 0.059 & 0.202 & 0.228 \\
\hline BYS, \% & -0.151 & -0.049 & 0.129 \\
\hline $\mathrm{pH},(1: 1)$ & 0.017 & -0.137 & 0.115 \\
\hline $\mathrm{EC}, \mathrm{dS} \mathrm{m}^{-1}(1: 1)$ & 0.194 & 0.181 & 0.307 \\
\hline $\mathrm{CaCO}_{3}, \%$ & 0.266 & 0.182 & -0.070 \\
\hline $\mathrm{OM}, \%$ & 0.059 & 0.321 & 0.140 \\
\hline $\mathrm{N}, \%$ & 0.189 & 0.328 & 0.336 \\
\hline $\mathrm{P}, \mathrm{ppm}$ & 0.172 & 0.258 & $0.382^{*}$ \\
\hline $\mathrm{K}, \mathrm{cmol} \mathrm{kg}^{-1}$ & 0.321 & 0.142 & $0.384^{*}$ \\
\hline $\mathrm{Ca}+\mathrm{Mg}, \mathrm{cmol} \mathrm{kg}$ & 0.213 & 0.267 & 0.004 \\
\hline $\mathrm{Na}, \mathrm{cmol} \mathrm{kg}^{-1}$ & 0.000 & $0.389^{*}$ & -0.347 \\
\hline $\mathrm{KDK}, \mathrm{cmol} \mathrm{kg}{ }^{-1}$ & 0.213 & 0.280 & -0.006 \\
\hline $\mathrm{Fe}, \mathrm{ppm}$ & 0.101 & -0.090 & -0.004 \\
\hline Mn, ppm & -0.339 & -0.108 & -0.365 \\
\hline $\mathrm{Cu}, \mathrm{ppm}$ & $0.484^{* *}$ & 0.230 & 0.273 \\
\hline $\mathrm{Zn}, \mathrm{ppm}$ & -0.026 & 0.275 & -0.254 \\
\hline
\end{tabular}

** $\mathrm{p} \leq 0.01$ hata düzeyinde çok önemli, * $\mathrm{p} \leq 0.05$ hata düzeyinde önemli

Çizelge 4. Soyada bitki boyu, bin tane ağırlı̆̆ 1 ve tane verimi ile toprakların bazı fiziksel ve kimyasal özellikleri arasındaki regresyon modeller

Table 4. Regression models among the plant height, thousand-seed-weight and grain yield in soybean with some physical and chemical properties of soils

\begin{tabular}{|c|c|c|c|c|}
\hline & Modeller & $\mathrm{R}$ & $\mathrm{F}$ & $\mathrm{p}$ \\
\hline & $\begin{array}{l}\mathrm{BB}=81.7-0.111 \mathrm{KDK}+0.909 \mathrm{CaCO}_{3}+0.021 \mathrm{P}+3.72 \mathrm{Cu}+39.9 \sqrt{N} \\
-1.03(\mathrm{Db} \times \mathrm{BYS})+0.120(\mathrm{Db} \times \mathrm{Kil})\end{array}$ & 0.669 & 2.32 & 0.062 \\
\hline 2. & $\begin{array}{l}\mathrm{BB}=14.5-6.59 \mathrm{OM}+112 \mathrm{~N}+0.012 \mathrm{P}+26.1 \mathrm{~K}+0.00246(\mathrm{KDK})^{2} \\
+92.1 \sqrt{\mathrm{Db}}-2.59(\mathrm{Db} \times \mathrm{BYS})+0.105 \mathrm{SN}+0.441 \mathrm{Kil}\end{array}$ & 0.727 & 2.24 & 0.070 \\
\hline 3. & $\begin{array}{l}\mathrm{BB}=77-17.7(\mathrm{EC})^{2}-0.638(\mathrm{OM})^{2}+136 \mathrm{~N}+2.55 \mathrm{Cu}+19.7 \mathrm{~K} \\
+4 \mathrm{Db}+1.04 \mathrm{Kil}-0.36(\mathrm{Db} \times \mathrm{Kil})+0.368 \mathrm{SN}-3.78 \mathrm{BYS}+17 \sqrt{\mathrm{Db}}\end{array}$ & 0.766 & 2.07 & 0.091 \\
\hline 4. & $\begin{array}{l}\mathrm{BTA}=305-139 \mathrm{EC}+2.59 \mathrm{CaCO}_{3}+165 \mathrm{~N}+0.727 \mathrm{P}-12.0 \mathrm{~K} \\
+82(\mathrm{EC})^{2}-114 \sqrt{\mathrm{Db}}-0.058(\mathrm{Db} \times \mathrm{Kil})+1.55 \mathrm{SN}\end{array}$ & 0.648 & 1.45 & 0.241 \\
\hline & $\begin{array}{l}\mathrm{BTA}=591-20.5 \mathrm{EC}+2.50 \mathrm{CaCO}_{3}+0.147(\mathrm{Ca}+\mathrm{Mg})+154 \mathrm{~N}+0.871 \mathrm{P} \\
-23.2 \mathrm{~K}-0.47(\mathrm{OM})^{2}-301 \sqrt{\mathrm{Db}}+3.33(\mathrm{Db} \times \mathrm{Kum})+1.08 \mathrm{SN}-42.9 \sqrt{K u m}\end{array}$ & 0.703 & 1.42 & 0.253 \\
\hline 6. & $\begin{array}{l}\mathrm{BTA}=648+0.00176(\mathrm{KDK})^{2}+0.155\left(\mathrm{CaCO}_{3}\right)^{2}+194 \mathrm{~N}+0.808 \mathrm{P} \\
-13.7 \mathrm{~K}-1.95 \mathrm{Na}-0.16(\mathrm{OM})^{2}-39.9(\mathrm{EC})^{2}-253 \sqrt{\mathrm{Db}}+2.72(\mathrm{Db} \times \mathrm{Kum}) \\
+4.83 \mathrm{SN}-3.84 \mathrm{TK}-44.7 \sqrt{\mathrm{Kum}}-0.396 \text { Silt }\end{array}$ & 0.782 & 1.46 & 0.250 \\
\hline 7. & $\mathrm{TV}=-50-19 \mathrm{EC}-29.1 \mathrm{OM}+1105 \mathrm{~N}+2.51 \mathrm{Kil}+192 \mathrm{Db}+4.78 \mathrm{SN}$ & 0.596 & 1.93 & 0.123 \\
\hline 8. & $\begin{array}{l}\mathrm{TV}=471-7.46(\mathrm{OM})^{2}-158(\mathrm{EC})^{2}+1481 \mathrm{~N}+3.60 \mathrm{P}+23 \mathrm{~K}-3.77 \mathrm{Mn} \\
-2.16 \mathrm{Silt}-1.39 \mathrm{Kum}+2.45(\mathrm{Db} \times \mathrm{Kil})+6.88 \mathrm{SN}-16.2 \mathrm{BYS}\end{array}$ & 0.709 & 1.47 & 0.234 \\
\hline & $\begin{array}{l}\text { TV }=-9-3.05 \mathrm{KDK}-178 \mathrm{EC}-35.0 \mathrm{OM}+1893 \mathrm{~N}+4.27 \mathrm{P}-158 \mathrm{Zn}+20.7 \mathrm{Cu}+13.9 \mathrm{Kil}- \\
0.03 \mathrm{Kum}-9.8(\mathrm{Db} \times \mathrm{Kil})+167(\mathrm{Db})^{2}-10.4(\mathrm{Db} \times \mathrm{BYS})+8.64 \mathrm{TK}\end{array}$ & 0.853 & 2.90 & 0.029 \\
\hline
\end{tabular}

BB: Bitki boyu, cm; BTA: Bin tane ağırlığı, g; TV: Tane verimi $\mathrm{kg} \mathrm{da}^{-1}$; EC: Elektriksel iletkenlik, $\mathrm{dS} \mathrm{m}^{-1}$; OM: Organik madde, $\%$; $\mathrm{CaCO}_{3}$ : Kireç, \%; N: Azot, \%; P: Fosfor, ppm; K: Potasyum, cmol kg-1 Mn: Mangan, cmol kg ${ }^{-1}$; Cu: Bakır, cmol kg ${ }^{-1}$ Zn: Çinko, cmol kg${ }^{-1}$; Db: Hacim ağırlığı, $\mathrm{g} \mathrm{cm}^{-3}$; SN: Solma noktası, \%; TK: Tarla kapasitesi, \%. 
Soya bitki boyu ile toprakların bazı fiziksel ve kimyasal özellikleri arasındaki (1)-(3) regresyon modellerinden (Çizelge 4) görüldüğ̈̈ gibi, regresyon katsayıları 0.669 ile 0.766 ; F değerleri 2.07 ile 2.32; p değerleri ise 0.062 ile 0.091 arasında değişmektedir. F değeri etkileşim ve ana etkenlerin anlamlı olup olmadığını belirlemek için yapılmakta, p değeri azaldıkça F'nin değeri artmaktadır. Kil, Db, EC, OM, N, $\mathrm{K}, \mathrm{Cu}, \mathrm{BYS}, \mathrm{SN}$ parametrelerini ve bu parametre değerlerinin karesini, çarpımını, karekökünü de kapsayan 3. modelde belirleme katsayısı en yüksek $(\mathrm{R}=0.766) ; \mathrm{Db}, \mathrm{EC}, \mathrm{BYS}, \mathrm{CaCO}_{3}$ ve kil içeren 1 . modelde ise en düşük $(\mathrm{R}=0.507)$ saptanmıştır. $\mathrm{p}$ değerlerine göre tüm modeller istatistiksel olarak anlamlılık $(\mathrm{p}<0.10)$ eğilimi dahilinde bulunmuştur. BTA ile toprakların bazı fiziksel ve kimyasal özellikleri arasındaki modellerin regresyon katsayıları 0.648 ile 0.782 arasında değişmektedir. Soya bin tane ağırlığı ile toprakların bazı fiziksel ve kimyasal özellikleri arasında istatistiksel olarak anlamlı farklıl1k saptanmamasına rağmen, 6. modelde belirleme katsayısı $(\mathrm{R}=0.782)$ yüksek düzeyde saptanmıştır. Elde edilen regresyon ilişkilerinde toprak özelliklerinin farklı biçimlerde nicel olarak dahil edilmesi modellerin performansını yükseltmiştir. Yapılan araştırmalar, regresyon modellerinin toprak özelliklerinin karesi, karekökü ve çarpımını kapsayan polinomlarla ifadesinin, belirleme katsayısını, dolayısıyla tahminin önem düzeyini yükselttiğini göstermektedir (Kosheleva ve ark., 2002; Gülser ve Candemir, 2014). Soya tane verimi ile toprakların KDK, OM, N, kum, kil, TK gibi fiziksel ve kimyasal özellikleri arasında oluşturulan regresyon modellerinde regresyon katsayıları 0.596 ile 0.853 ; F değerleri 1.47 ile 2.90 arasında, p değerleri ise 0.029 ile 0.234 arasındadır (Çizelge 4). En yüksek belirleme katsayıs1 $\quad(\mathrm{R}=0.853) \quad 9$. modelde ve istatistiksel anlamlılık $(\mathrm{p}<0.05)$ düzeyinde bulunmuştur. Murty (2002) yaptığı bir araştırmada, meteorolojik parametreler ile soya bitkisinin bitki boyu, 100 tane ağırlığı ve tane verimi arasında regresyon modelleri oluşturmuştur. Araştırmacı, bitki boyu, 100 tane ağırlığı ve tane verim modelleri için çoklu regresyon katsayı $\left(\mathrm{R}^{2}\right)$ değerlerini sırasıyla $0.97 ; 0.93 ; 0.93$ olarak saptamıştır. Adams ve ark. (2017), soya bitki veriminin 2688-7324 $\mathrm{kg} \mathrm{ha}^{-1}$ aralığında değişmesi durumunda, verimlilik düzeylerini göz önüne alarak verim ile toprağın fiziksel ve kimyasal özellikleri (kil, EC, P,K, $\mathrm{Ca}, \mathrm{Mg}, \mathrm{S}, \mathrm{Fe}, \mathrm{Zn}, \mathrm{B}, \mathrm{tC}$ ) arasında oluşturdukları regresyon modellerinde, orta ve yüksek verim düzeyinde belirleme katsayılarını sırasıyla 0.51 ve 0.73 olarak belirlemişlerdir. Fageria ve ark. (2014) tarafindan, jips ve kirecin soya verimi ve verim unsurları üzerine yaptıkları bir araştırmada, verim ile toprağın kimyasal özellikleri arasındaki ilişkilerin belirlenmesinde $\mathrm{Y}=\mathrm{f}(\mathrm{x})$ biçiminde ikinci dereceden regresyon denklemlerinden kullanılmış, belirleme katsayıları ise zayıf, orta ve yüksek düzeyde saptanmıştır.

\subsection{Agronomik Parametreler ile Toprak Özellikleri Arasinda Oluşturulan Regresyon Modellerin Geçerlilikleri}

Deneysel verilere göre elde edilen regresyon modellerin geçerliliklerinin belirlenmesinde, modellerin oluşturulmasında kullanılan değerler dışındaki veya veri bankasındaki değerlerden kullanılması gerekmektedir (Wang ve ark., 2016). Soya bitkisinin BB, BTA ve TV ile toprakların bazı fiziksel ve kimyasal özellikleri arasındaki regresyon modellerinin geçerliliğinin belirlenmesine ait istatistiksel parametreler Çizelge 5'te verilmiștir. Cizelge 5 'ten görüldüğü gibi, modelin uygunluk indeksi (d) 1'e yakın, modelin etkinliği 1'den büyük olmakta, hata kareler ortalamasını karekökü ise yüksek olmamakta, aynı zamanda $d$ değerleri ME'den büyük olmaktadır. Dolayısıyla, regresyon modellerine ait istatistiksel göstergeler genel olarak, geçerlilik sınırları dahilinde değişmektedir (Krause ve ark., 2005; Wang ve ark., 2016). Souza ve ark. (2011) tarafindan Kuzeydoğu Amozanda doğal koşullarda soya bitkisinin büyüme ve verim modellerinin geçerliliğinin belirlenmesine ait bir çalışmada, HKOK, d ve ME değerlerini sırasıyla 197.66; 0.88; 0.61 olarak tespit etmişlerdir. Kumar ve ark. (2008) tarafindan yapılan bir araştırmada, farklı 3 çeşit soya bitkisinin tane verimlerinin tahmini için kullandıkları modele ait HKOK değerlerini sırasıyla $86.0 \mathrm{~kg} \mathrm{ha}^{-1}, 123.9 \mathrm{~kg} \mathrm{ha}^{-1} ; 28.6 \mathrm{~kg} \mathrm{ha}^{-1}$ olarak hesaplanmışlardır.

Çizelge 5. Soya bitki boyu (BB), bin tane ağırllı̆g 1 (BTA) ve tane verimine (TV) ait regresyon modellerin bazı istatistiksel parametreleri

Table 5. Some statistical parameters of regression models of soybean plant height (BB), thousand-seed-weight (BTA) and grain yield (TV)

\begin{tabular}{lcccc}
\hline \hline Modeller (No) & $\mathrm{R}$ & HKOK & $d$ & ME \\
\hline BB (3) & 0.766 & 8.144 & 0.993 & 0.399 \\
BTA (6) & 0.782 & 23.581 & 0.976 & -2.565 \\
Y (9) & 0.853 & 29.882 & 0.995 & 0.615 \\
\hline
\end{tabular}

BB: Bitki boyu, BTA: Bin tane ağırlı̆̆ı, TV: Tane verimi, R: Belirleme katsayısı, HKOK: Hata kareler ortalamasının karekökü, d: Uygunluk indeksi, ME: Modelin etkinliği 
Regresyon modellerin yapılmasındaki bazı sinırlamalara rağmen, modelin yapılmasının ve uygulamasının kolay olması araştırmacılar için avantaj sağlamaktadır (Tamari ve ark., 1996; Schaap ve ark., 2001). Regresyon modellerinin toprak özelliklerine, çevresel değişkenlere bağlı olarak toprak özelliklerinin mekânsal değişimine dayanan sinıflandırması da söz konusu olmaktadır (Minasny ve McBratney, 2008).

Soya bitki boyu, bin tane ağırlığı, tane veriminin üçüncü modele göre hesaplanan ve ölçülen değerlerin karşılaştırılması Şekil 2'de verilmiştir. Soya BB, BTA,
TV ile toprakların fiziksel ve kimyasal özellikleri arasındaki regresyon modellere göre hesaplanan ve ölçülen değerler arasındaki korelasyon değerleri sirasıyla $0.726,0.804$ ve 0.753 olup, 0.01 düzeyinde istatistiksel olarak anlamlı bulunmuştur. Şaylan (1996) tarafından soya bitkisinin gelişimi ve veriminin tahmin edilmesine ait yapılan bir modelleme araştırılmasında, hesaplanan verimin gerçek verimden \%14.6 düzeyinde daha yüksek olduğu saptanmıştır. Araştırıcı, bu farklılığın, modelin deneme alanına göre düzenlenmemesinden kaynaklanabileceğini bildirmiştir.

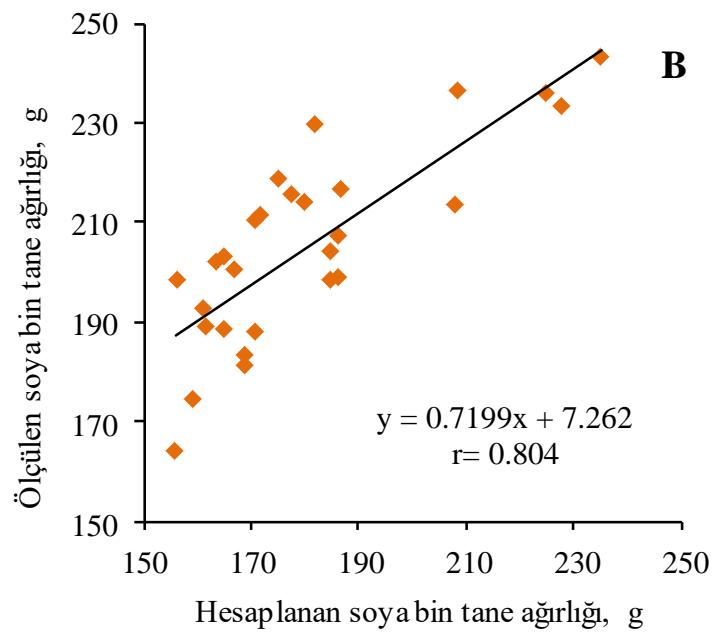

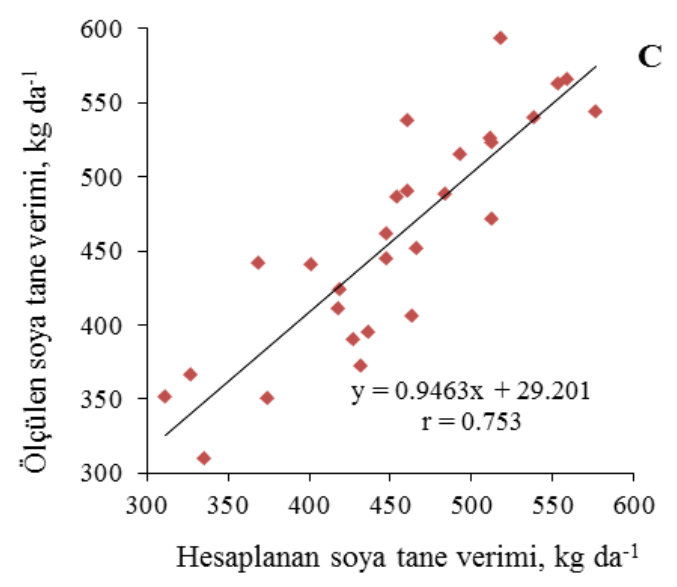

Şekil 2. Soya bitki boyu (A), bin tane ağırlığı (B), tane veriminin (C) hesaplanan ve ölçülen değerler arasındaki ilişki

Figure 2. Relationship between calculated and measured values of soybean plant height (A), thousand-seed-weight $(B)$, grain yield $(C)$

\section{Sonuç ve Öneriler}

Toprakların fiziksel ve kimyasal özelliklerinin değişimi, bitki verimine önemli düzeyde etki yapan faktörlerden biridir. Çarşamba Ovası'nda geleneksel toprak işleme yöntemleriyle ana ürün olarak soya bitkisi yetiştirilen tarım alanlarının bazı fiziksel ve kimyasal özellikleri ve soya bitkisinin agronomik parametreleri belirlenmiş; bu özellikler arasındaki korelasyon ilişkiler saptanmış ve bitkilerin bazı agronomik özellikleri ile toprakların bazı fiziksel ve kimyasal özellikleri arasında 
regresyon modelleri oluşturulmuştur. Soya bitki boyu ile toprakların $\mathrm{KDK}, \mathrm{CaCO}_{3}, \mathrm{P}, \mathrm{Cu}, \mathrm{N}, \mathrm{Db}, \mathrm{BYS}$, kil özellikleri arasındaki regresyon modeline, OM, EC, SN, $\mathrm{K}$ özelliklerinin dahil edilmesi belirleme katsayısını yükseltmiştir. Bin tane ağılık ile toprakların EC, $\mathrm{CaCO}_{3}, \quad \mathrm{~N}, \mathrm{P}, \mathrm{K}, \mathrm{Db}$, kil, SN özellikleri arasında oluşturulan modele $\mathrm{OM}$, kum, silt, $\mathrm{TK}, \mathrm{Na}, \mathrm{Ca}+\mathrm{Mg}$, KDK; tane verim ile EC, OM, N, kil, Db, SN arasinda oluşturulan modele ise TK, BYS, kum, silt, KDK, P, K, $\mathrm{Mn}, \mathrm{Zn}, \mathrm{Cu}$ değerlerinin ilave edilmesi belirleme katsayısını artırmıştır. Tüm regresyon modellerinin, toprak özellikleri değerlerinin çarpımını, karesini ve karekökünü içeren çokterimli ile ifade edilmesi de belirleme katsayısının yükselmesine eki yapan faktördür. Ölçülen ve regresyon modellerine göre hesaplanan agronomik parametrelerin karşılaştırılması; elde edilen regresyon modellerin araştırma bölgesinin soya yetiştirilen topraklarında parametrelerin tahmini için uygulanabilirliğini göstermiş̦tir. Bu modellerin daha yüksek düzeydeki başarısı, soya bitkisinin optimum verim seviyesine sahip olduğu alanlarda yapılacak çalışmalara bağlıdır. Tahmin sonuçlarının daha iyi olması için, tarımsal ve çevresel faktörlerin modellere dahil edilmesinin gerekliliği düşünülebilir. Regresyon modellerin oluşturulmasının ve uygulanmasının kolaylığı dikkate alınarak, yerel ve bölgesel düzeyde çeşitli bitkiler için farklı regresyon modellerin yapılabilmesi için, toprak özelliklerine ve bitkilerin verim unsurlarına ait veri bankasının oluşturulması önemlidir. Modelin uygulanabilirliğinin belirlenmesinde toprak ve iklim koşullarının benzer olduğu çalışma alanlarının toprak ve bitki verilerinden kullanılması gerekmektedir. Tarımsal işlemlerin düzenli yapılmaması, iklim koşullarının değişimi sonucunda toprak özelliklerinin ve ürün miktarının optimum düzeyde olmaması gibi faktörler, hesaplanan ve ölçülen verim değerleri arasındaki farklılıkların ortaya çıkmasına, dolayısıyla da pratikte uygulanabilir modellerin yapilmamasina neden olabilmektedir. Regresyon modellerin geliştirilmesi toprak bilgi sistemlerinin ayrılmaz bir parçası olacaktır.

\section{Kaynaklar}

Adams, T.C., Brye, K.R., Purcell, L.C., Ross, J., Gbur, E.E., Savi, M.C., 2017. Soil property predictors of soybean yield using yield contest sites. Journal of Crop Improvement, 31(6): 816-829.

Alexandrov, V.A., Hoogenboom, G., 2000. The impact of climate variability and change on crop yield in Bulgaria. Agricultural and Forest Meteorology, 104(4): 315-327.

Anonim, 1984. Samsun İli Arazi Varlığı. T.C. Tarım Orman ve Köy İşleri Bakanlığı, Toprak Su Genel Müdürlüğü Yayınları, İl Rapor No: 55; Genel Yayın No: 748, Ankara.

Anonim, 2013. Tohumluk Tescil ve Sertifikasyon Merkez Müdürlüğü.
(https://www.tarimorman.gov.tr/BUGEM/TTSM/Be 1geler/Tescil/Teknik\%20Talimatlar/End\%C3\%BCstr i\%20Bitkileri/soya.pdf) (Erişim tarihi: 25.01.2019)

Anonim, 2016. Türkiye İstatistik Kurumu Temel İstatistikler. http://www.tuik.gov.tr (Erişim Tarihi: 17.04.2017).

Anonymous, 1954. U.S. Salinity Laboratory Staff. Diagnosis and Improvement of Saline and Alkaline Soils. (Ed L.A. Richards). USDA Agriculture

Handbook No: 60, U.S. Goverment Printing Office, Washington.

Arıŏlu, H., 2000. Yağ Bitkileri Yetiştirme Ve Islahı. Ders Kitapları Yayın No:A-70C. Çukurova Üniversitesi Ziraat Fakültesi Genel Yayın No:220, Adana.

Arslanoglu, F., Aytac, S., Karaca E., 2005. The Determination of yield criteria of some soybean (Glycine max L.) varieties sowed in Samsun and Sinop locations for second crop production. The Sixth Field Crops Congress of Turkey. In: M. Karaca and M. Bilgen (Editors), Proceeding, vol I: 387-392.

Ay, B., 2012. Türkiye'de sslah edilmiş yeni soya (Glycine Max. L. Merrill) çeşitlerinin Orta Karadeniz Bölgesi koşullarında verim ve kalite performanslarının belirlenmesi. Yüksek Lisans Tezi, Ondokuz Mayıs Üniversitesi Fen Bilimleri Enstitüsü Tarla Bitkileri Anabilim Dalı, 51, Samsun.

Bayrakl1, F., 1987. Toprak ve Bitki Analizleri. Ondokuz Mayıs Üniversitesi Yayınları, No:17, Samsun.

Bayrakl1, F., Ekberli, İ., Gülser, C., 1999. Azerbaycan Mil ovası topraklarının verimlilik düzeylerinin deneysel ve matematiksel olarak değerlendirilmesi. Ondokuz Mayıs Üniversitesi Ziraat Fakültesi Dergisi, 14(2): 138-153.

Black, C.A., 1965. Methods of Soil Analysis Part IPhysical and Mineralogical Methods. Soil Science Society of America, No: 9, USA.

Bouma, J., Van Lanen, H.A.J., 1987. Transfer functions and threshold values: from soil characteristics to land qualities. In Proceedings of the International Workshop on Quantified Land Evaluation Procedures, Washington, DC, USA, pp.106-110.

Budka, A., Lacka, A., Gaj, R., Jajor, E., Korbas, K., 2015. Predicting winter wheat yields by comparing regression equations. Crop Protection, 78: 84-91.

Campbell, G.S., Shiozawa, S., 1992. Prediction of hydraulic properties of soils using particle-size distribution and bulk density data. In: Van Genuchten, M.T., Leij, F.J., Lund, L.J. (Eds.). Proceedings of International Workshop on Indirect Methods for Estimating the Hydraulic Properties of Unsaturated Soils. University of California, Riverside, pp. 317-328.

Çetin, H., 2010. Soyada fosforlu gübrelemenin verim ve kalite unsurlarına etkilerinin belirlenmesi ve Konya yöresinde soya için uygun fosfor dozunun tespit edilmesi. Yüksek Lisans Tezi, Selçuk Üniversitesi 
Fen Bilimleri Enstitüsü Tarla Bitkileri Anabilim Dalı. Konya.

Demiralay, İ., 1993. Toprak Fiziksel Analizleri. Atatürk Üniversitesi Ziraat Fakültesi Yayınları No: 143, Erzurum.

Dengiz, O., Ekberli, İ., 2017. Bazı vertisol alt grup topraklarının fizikokimyasal ve isısal özelliklerinin incelenmesi. Akademik Ziraat Dergisi, 6(1): 45-52.

Dorsey, J.W., Hardy, L.C., 2018. Sustainability factors in dynamical systems modeling: Simulating the nonlinear aspects of multiple equilibria. Ecological Modelling, 368: 69-77.

Dotlacil, L., Toman, K., 1991. Testability of the yield of different wheat varieties. Rostlinna Vyroba, 37:3338.

Ekberli, İ., Dengiz. O., 2016. Bazı inceptisol ve entisol alt grup topraklarının fizikokimyasal özellikleriyle 1sısal yayınım katsayısı arasındaki regresyon ilişkilerin belirlenmesi. Toprak Su Dergisi, 5(2): 110.

Ekberli, İ., Kerimova, E., 2005. Azerbaycan'ın Şirvan bölgesinde sulanan killi bir toprağın bazı fizikselkimyasal parametrelerinin değişimi. Ondokuz Mayıs Üniversitesi Ziraat Fakültesi Dergisi, 20(3): 54-59.

Fageria, N.K., Moreira, A., Moraes, L.A.C., Moraes, M.F., 2014. Influence of lime and gypsum on yield and yield components of soybean and changes in soil chemical properties. Communications in Soil Science and Plant Analysis, 45: 271-283.

Gülser, C., 2004. Tarla kapasitesi ve devamlı solma noktası değerlerinin toprakların fiziksel ve kimyasal özellikleriyle ilişkili pedotransfer eşitliklerle belirlenmesi. Ondokuz Mayis Üniversitesi Ziraat Fakültesi Dergisi, 19(3): 19-23.

Gülser, C., Candemir, F., 2014. Using soil moisture constants and physical properties to predict saturated hydraulic conductivity. Eurasian Journal of Soil Science 3(1): 77-81.

Gülser, C., Ekberli, I., Candemir F., 2016. Spatial variability of soil physical properties in a cultivated field. Eurasian Journal of Soil Science, 5(3): 192200.

Hallauer, A.B., Miranda Fo, J.B., 1987. Quantitative Genetics in Maize Breeding. Lowa State University. Press, Ames, Lowa.

Homer, A. D., Özçelik, H., Üstün, A., 2000. Karadeniz bölgesi soya 1slahı çalışmaları. Karadeniz Tarımsal Araştırma Enstitüsü Samsun, 1999 Y1lı Teklif, Gelişme ve Sonuç Raporları, S: 22-30, Samsun.

Huang, F., Zhan, W., Ju, W., Wang, Z., 2014. Improved reconstruction of soil thermal field using two-depth measurements of soil temperature. Journal of Hydrology, 519: 711-719.

Kacar, B., 1994. Bitki ve Toprağın Kimyasal Analizleri III, Toprak Analizleri. Ankara Üniversitesi Ziraat Fakültesi, Eğitim Araştırma ve Geliştirme Vakfı Yayınları, No: 3, Ankara.
Karagül, E.T., Ay, N., Meriç, Ş., Huz, E., 2011. Ege Bölgesi'nde ana ürün olarak yetiştirilen bazı soya genotiplerinin verimi, verim öğeleri ve nitelikleri üzerinde bir araştırma. Journal of Anadolu, 21(2): 59-66.

Kars, N., Ekberli, İ., 2019a. Çarşamba Ovasının buğday bitkisi altındaki topraklarının bazı fiziksel ve kimyasal özelliklerinin incelenmesi. Toprak $\mathrm{Su}$ Dergisi, 8(1): 18-28.

Kars, N., Ekberli, İ., 2019b. Buğday bitkisinin verim parametreleri ile bazı toprak özellikleri arasındaki pedotransfer modellerin uygulanabilirliği. Türkiye Tarımsal Araştırmalar Dergisi, 6(2): 153-164.

Kosheleva, N.E., Kasimov, N.S., Samonova, O.A., 2002. Regression models fort he behavior of heavy metals in soils of the Smolensk-Moskow upland. Pocvovedeniye, 8: 954-966.

Krause, P., Boyle, D.P., Base, F., 2005. Comparison of different efficiency criteria for hydrological model assessment. Advances in Geosciences, 5: 89-97.

Kumar, P., Sarangi, A., Singh, D.K., Parihar, S.S., Sahoo, R.N., 2015. Simulation of salt dynamics in the root zone and yield of wheat cropunder irrigated saline regimes using SWAP model. Agricultural Water Management, 148: 72-83.

Lindsay, L., Norvell, W.A., 1978. Development of a DTPA soil test for zinc, iron, manganese and copper. Soil Science Society of America Journal, 42(3): 421428.

Maiti, R., Wersche-Ebeling, P., 1998. Maize Science. Science Publichers, Incorporation USA, ISBN 157808-019-3, pp.519.

Manzoor, A.A.B., Kaleri, K.K., 1971. Correlation in studies in soybean (Glycine $\max$ L.) Merrill. Agriculture of Pakistan, 22(2):155-163. (From PBA 43(8), No.6461, 1973).

Marin, A., 1975. The inheritance of some quantitative characters in soybean and the existence of correlations between them. Biuletyn Instytutu Hodowli aklimatyzacji Roslin No.128/129, 59-62. (From PBA 50(5), No.4590, 1980).

Minasny, B., McBratney, A.B., 2008. Regression rules as a tool for predicting soil properties from infrared reflectance spectroscopy. Chemometrics and Intelligent Laboratory Systems, 94: 72-79.

Murthy, V.R.K., 2002. Crop growth modeling and its applications in agricultural meteorology. Satellite Remote Sensing and GIS Applications in Agricultural Meteorology, 235-261.

Overman, A.R., Scholtz III, R.V., 2002. Mathematical Models of Crop Growth and Yield. Marcel Dekker, Inc., New York.

Pachepsky, Y.A., Rawls, W.J., 2004. Development of pedotransfer functions in soil hidrology. Develoment in Soil Science, 30: 497p.

Peterson, C.J., Graybosch, R.A., Baenziger, P.S., Grombacher, A.W., 1992. Genotype and 
environment effects on quality characteristics of hard red winter wheat. Crop Science, 32(1): 98-103.

Rajput, M.A., Sarwar, G., Tahir. K.H., 1987. Variability for some quantitative traits in soybean. Soybean Genetics Newsletter, 14: 113-116.

Richards, L.A., 1954. Diagnosis and Improvement of Saline and Alkali Soils. United States Department of Agriculture, Handbook No: 60, pp. 105-106.

Sağlam, M.T., 1997. Toprak ve Suyun Kimyasal Analiz Yöntemleri. Tekirdağ Üniversitesi Ziraat Fakültesi Yayınları, No: 189.

Schaap, M.G., Leij, F.J., van Genuchten, M.T., 2001. ROSETTA: A computer program for estimating soil hydraulic parameters with hierarchical pedotransfer functions. Journal Hydrology, 251: 163-176.

Simpson, Jr.A.M., Wilcox, J.R., 1983. Genetic and phenotypic associations of agronomic characteristics in four high protein soybean population. Crop Science, 23: 1077-1081.

Souza, P.J. de O.P. de., Farias, J.R.B., Abreu, J.P.M. de M. e., Ribeiro, A., Rocha, E.J.P. da., Botelho, M. do N., Sousa, A.M.L. de., 2011. Simulation of soybean growth and yield under northeastern Amazon climatic conditions. Pesquisa Agropecuária Brasileira, 46(6): 567-577.

Şaylan, L., 1996. Soya veriminin CRPSM modeli ile belirlenmesi. Kültür Teknik Derneği Toprak Su Dergisi, 5(1): 12-17.

Taban, S., Çıkılı, Y., Kebeci, F., Taban, N., Sezer, S.M., 2004. Taşköprü yöresinde sarımsak tarımı yapılan toprakların verimlilik durumu ve potansiyel beslenme problemlerinin ortaya konulması. Tarım Bilimleri Dergisi, 10(3): 297-304.

Tamari, S., Wösten, J.H. M., Ruiz-Suárez, J.C., 1996. Testing an artifi cial neural network for predicting soil hydraulic conductivity. Soil Science Society of America Journal, 60: 1732-1741.

Tayyar Ş., Gül, M.K., 2007. Bazı soya fasulyesi (glycine $\max (1$.$) merr.) genotiplerinin ana ürün$ olarak Biga şartlarındaki performansları. Yüzüncü Y1l Üniversitesi, Ziraat Fakültesi, Tarım Bilimleri Dergisi, 17(2): 55-59.

Thiery, D., Amraoui, N., Noyer, M.L., 2018. Modelling flow and heat transfer through unsaturated chalkValidation with experimental data from the ground surface to the aquifer. Journal of Hydrology, 556: 660-673.

Turan, M., Dengiz, O., Turan Demirağ, İ., 2018. Samsun ilinin Newhall modeline göre Toprak sıcaklık ve nem rejimlerinin belirlenmesi. Türkiye Tarımsal Araştırmalar Dergisi, 5(2): 131-142.

Valdivia, V., 1983. International Soybean Variety Experiment. Seventh Report of Results 1979. INTSOY Series Number 24. Collage of Agriculture University of İllinois at Urbana-Champaing, 64-65.

Vereecken, H., Weynants, M., Javaux, M., Pachepsky, Y., Schaap, M.G., van Genuchten, M.T., 2010. Using pedotransfer functions to estimate the van
Genuchten-Mualem soil hydraulic properties: A review. Vadose Zone Journal, 9(4): 795-820.

Wang, L., Lia, X., Chen, Y., Yang, K., Chen, D., Zhou, J., Liu, W., Qi, J., Huang, J., 2016. Validation of the global land data assimilation system based onmeasurements of soil temperature profiles. Agricultural and Forest Meteorology, 218-219: 288297.

Whitman, C.E., Haffield, J.L., Reginato, R.J., 1985. Effect of slope position on the microclimate, growth, and yield of barley. Agronomy Journal, 77(5): 663669.

Willmott, C.J., Matsuura, K., 2005. Advantages of the mean absolute error (MAE) over the root mean square error (RMSE) in assessing average model performance. Climate Research, 30(1): 79-82.

Willmott, C.J., Robeson, S.M., Matsuura, K., 2012. Short Communication. A refined index of model performance. International Journal of Climatology, 32(13): 2088-2094. 